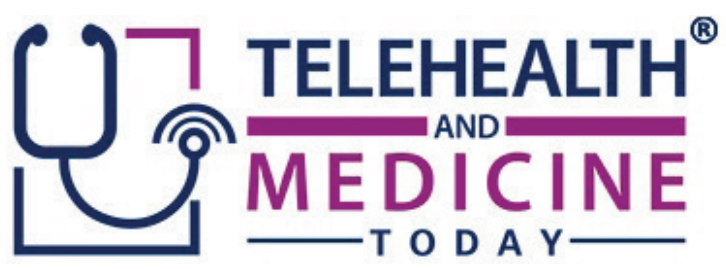

$\underset{\text { Crickitoripdatios }}{\text { Cross }}$

\title{
Maximizing Your Telehealth Return on Investment (ROI): Five Best Practices to Increase Billing and Reimbursement
}

\author{
Monica Leslie Nash ${ }^{1}$, Bryan T. Arkwright ${ }^{1,2,3,4}$
}

Author: ${ }^{1}$ Schumacher Clinical Partners, Lafayette, LA, USA, ${ }^{2}$ School of Law, Wake Forest University,

Winston-Salem, NC, USA, ${ }^{3}$ Cromford Health, Charlotte, NC, USA, ${ }^{4}$ Partners in Digital Health, New York, USA

Corresponding Author: Monica Leslie Nash, Email: Monica_Nash@schumacherclinical.com

Keywords: Business Model, Compliance, Data Analytics, Digital Health, Governance, Investment, Revenue, Startup, Telehealth, Telemedicine

Category: Methodologies, Original Market Research

The sheer volume of telehealth codes reimbursed continues to grow, as all payers (federal, state, and private) approve and incorporate new policies and codes. Despite additional codes and friendlier policies, organizations seeking to be paid for telehealth still struggle with interpreting and utilizing automated processes to maximize telehealth revenue. Key challenge areas for telehealth billing and reimbursement include, but are not limited to, compliance, regulation, documentation, and data management.

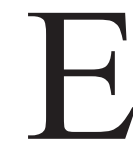
xperts in the field of telehealth predict big things for 2019. Although hopes are high for adoption by providers, patients, and payers, there is a constant thorn in the side of the industry - reimbursement. In a recent article on the Advisory Board website, only $21 \%$ of those providing telehealth were highly successful in achieving financial return for their virtual services. ${ }^{1}$

The good news is that it does not have to be so complicated. By adopting recommended best practices, an organization can create compliant, sustainable workflows that would meet requirements for coverage, coding, and documentation, while increasing reimbursement and overall program revenue. There are five best-practice criteria that organizations should place focus on when seeking to create not only a profitable telehealth program but also a program that is compliant with all relevant state, federal, and private payer policies and regulations (Table 1 ). 
Table 1. Five best practices for telehealth billing and reimbursement

\begin{tabular}{|l|}
\hline 1. Contracts and Agreements \\
\hline 2. Policy and Regulatory Requirements \\
\hline 3. Standard Operating Procedures \\
\hline 4. Smart Workflow Design \\
\hline $\begin{array}{l}\text { 5. Program Oversight, Documentation, and } \\
\text { Reporting }\end{array}$ \\
\hline
\end{tabular}

BEST PRACTICE AREA \#1: CONTRACTS AND AGREEMENTS

Organizations providing telehealth services can increase their opportunity to collect telehealth payments by ensuring that entities providing telehealth have contracts and agreements in place to clarify the obligation of all parties.

As a rule, each contract or agreement between two parties should include standard contractual provisions that capture the full scope of billing and compensation obligations, quality metrics and goals, the structure of the relationships, and expectations from technology from each party.

Many organizations have entered into telehealth programs without the appropriate contracts or arrangements in place, which exposes them to legal risk and decreases their potential for holding contracted parties to agreed-upon financial terms or responsibilities and tasks required for telehealth codes and collecting reimbursement.

\section{BEST PRACTICE AREA \#2: POLICY AND REGULATORY REQUIREMENTS}

Maximizing payments for telehealth services provided requires a continuous awareness and monitoring of the policy and regulatory environment, with the agility to change at the process and technical levels. Regulation of the telehealth industry continues to trend in a favorable direction; however, interpretation of the rules can vary tremendously from one state to another and from one payer to
Table 2. Considerations for successful reimbursement from payers

- Exact codes they will reimburse

- Sites eligible for service

- Providers eligible for service

- Modifiers and/or places of service required

- Payment of a facility fee in addition to a professional fee

another payer. Misinterpretation can mean denied claims that were eligible for payment.

To ensure collection of all available telehealth payments, programs should perform frequent reviews of their individual payer policies, as outlined in Table 2.

When claims are denied by a payer, it is most frequently because the required telehealth documentation is missing, such as a Place of Service or a modifier. For example, as of January 2018, Medicare requires that all telehealth codes have Place of Service 02 as part of the documentation, but no longer requires a modifier, while many other payers require the GT-(telehealth service rendered via interactive audio and video telecommunications system) or 95-(synchronous telemedicine service rendered via a real-time interactive audio and video telecommunications system) modifiers.

Tracking and working telehealth denials are important to ensure that any amendments to documentation are made within the limited timeframe to adjust and receive the expected associated reimbursement.

Additionally, organizations can exercise the ability to negotiate with payers to drive additional coverage for telehealth services not covered. However, having comprehensive data is critical to support their negotiations. 


\section{BEST PRACTICE \#3: STANDARD OPERATING PROCEDURES}

Winning telehealth programs utilize standard operating procedures (SOPs) to support implementation of effective billing and reimbursement processes throughout the telehealth development life cycle. Best practice approaches reinforce successful habits in the areas of contracting, policy trends and developments, new program start-ups, clinical documentation, and centralized revenue cycle practices, which in turn increase accurate and compliant telehealth billing.

A New Telehealth Service/Agreement Checklist is one example of a SOP tool that will assist new programs in start-up processes and ensure that all telehealth agreements, contracts, programs, and services have been clearly defined and approved using a standardized approach.

Another example of a tool that leads to the adoption of successful SOPs is a Telehealth Provider Guidebook that will assist with reinforcement of accurate and compliant clinical documentation processes. Keeping leadership aware of changes is critical, as multi-department collaboration may be required to modify and continuously improve the telehealth billing process.

\section{BEST PRACTICE \#4: SMART WORKFLOW DESIGN}

Thoughtful design of clinical, technical, operational, and financial workflows will place telehealth programs in the best position to collect available revenue for appropriate telehealth services. The use of automated systems, delineation of roles, and smart text/tools within the electronic medical record (EMR) aim to refocus from an individual process step and place it on ease of use for end-users. Greater diligence in planning workflow increases the likelihood that each billable telehealth visit will include the appropriate documentation, modifier, and code applied for payment.

One critical area where smart workflow design is imperative to capture available telehealth revenue is the technical build within the EMR. If an EMR is utilized for dropping bills, program leadership should work closely with EMR design experts to build out the required visit types, smart text and tables that support the telehealth billing requirements of their specific payers and their specific geography (Table 3 ).

\section{BEST PRACTICE \#5: PROGRAM OVERSIGHT, DOCUMENTATION,} AND REPORTING

Centralized program oversight with established program governance and real-time reporting capabilities will create full operational transparency to program performance. Financial metrics, such as total billed encounters, total successfully billed encounters, and total denied encounters, should be monitored regularly to maximize collections and identify and correct issues.

The difference between encounters billed and encounters successfully reimbursed should be analyzed further by frequency of denial reason

Table 3. A checklist of items for discussion with IT*_computer support

\begin{tabular}{|l|}
\hline - Telehealth place of service \\
\hline - Provider (distant site) is POS 02 \\
\hline - Patient (originating site) is address where \\
patient is located
\end{tabular}

*information technology; POS 2: place of service code 2 
to determine a true root cause of a missed revenue opportunity. Best practice programs perform these analyses on a regular basis, developing action plans and feedback loops to increase accuracy, quality, and revenue growth over time.

\section{CONCLUSION}

Although many moving pieces are required for a telehealth program to be in balance, the five best practices outlined here are intended to be adopted as a framework to drive financial viability of telehealth programs and services. Careful attention to each billing and reimbursement best practice in the areas of contracting, policy, procedures, workflow, and reporting will create a roadmap for excellence, outlining the specific details necessary to increase profitability, align stakeholder incentives, and improve telehealth program performance.

Funding Statement: This research received no specific grant from any funding agency in the public, commercial, or not-for-profit sectors.
Conflicts of Interest: The authors declare no conflicts of interest with respect to research, authorship and/or publication of this article.

Contributors: Ms Monica Leslie Nash and Mr Bryan T. Arkwright researched the topic and co-wrote the article.

\section{REFERENCE}

1. Hasan H. How to design a profitable staffing model for your telehealth strategy. Advisory Board. 2018, April 4. Accessed 3/10/19 from: https://www.advisory.com/ research/medical-group-strategy-council/ practice-notes/2018/04/telehealth-strategy

Copyright Ownership: This is an open access article distributed in accordance with the Creative Commons Attribution Non Commercial (CC BY-NC 4.0) license, which permits others to distribute, adapt, enhance this work non-commercially, and license their derivative works on different terms, provided the original work is properly cited and the use is noncommercial. See: http://creativecommons. org/licenses/by-nc/4.0. 